\title{
O Sistema na Codificação Civil Brasileira: de Leibniz a Teixeira de Freitas
}

Gudith OMaxtins- Costa

Professora Adjunta na Universidade Federal do Rio Grande do Sul. Doutora em Direito pela USP.

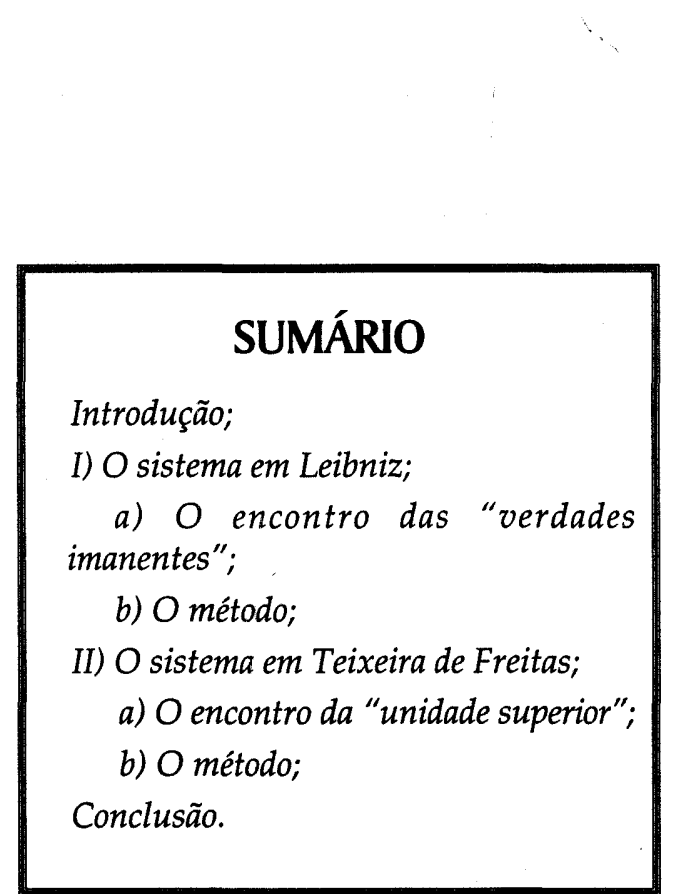

\section{Introdução}

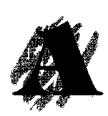

ssentado, na história da cultura jurídica, que o fenômeno da codificação corresponde à materialização, no direito de fonte legislativa, de uma certa noção de sistema, será interessante averiguar, na codificação civil brasileira, quais as linhas de influência que conformam o modelo de sistema que acolhemos. Proponho, para esta leitura, um prisma específico, qual seja, a noção de sistema que, acolhida por TEIXEIRA DE FREITAS ${ }^{1}$, acabou - apesar de certos rumos desviantes

1. Nunca será demasia destacar a importância da concepşão geral do direito que, marcando a formação cultural de Teixeira de Freitas, acabou por marcar a noção de sistema que pode ser deduzida do Código Civil. É que Freitas foi um fenômeno cultural de dificil explicaçáo. Romanista, por certo, mas năo só; atento cultor das fontes lusitanas, mas não só. Universalista, por certo, mas, ao mesmo tempo, um perso. nagem vincado pela atenção ao seu lugar - o dado espacial, ou os aspectos "espaciais" do sistema o seu país, ao qual escandaliza o fato de haver, já, um Código Comercial, e inexistir um equivalente no setor da agricultura, "o mais importante dos problemas a resolver" (Veiz-se neste sentido, a análise de Pierangelo Catalano na palestra proferida 
- por restar espelhada no Código Civil de 1916, vendo-se refletida em alguma medida ainda hoje, no Projeto do Código Civil, em tramitação na Câmara dos Deputados.

Sabe-se que na noção de sistema endossada por TEIXEIRA DE FREITAS foram fortíssimas as influências germânicas, notadamente a de SAVIGNY, objeto de estudos vários e proficientes que esgotam o tema ${ }^{2}$. Menos versada tem sido a influência do pensamento de $\mathrm{LEIBNIZ}^{3}$ na concepção

de sistema que está na raiz da Consolidação das Leis Civis e do Esboço. Muito embora este tema tenha sido objeto de certeiras análises ${ }^{4}$, os valiosíssimos estudos que o versam estão centrados, contudo, na noção de sistema que resulta e advém da célebre bipartição entre os direitos pessoais e os direitos reais, refletindo-se na estrutura do projetado Código ${ }^{5}$. Em outras palavras, estes estudos têm como eixo, fundamentalmente, a noção de sistema enquanto estrutura,

na Sessão Inaugural do Congresso Internazionale del Centenário di Augusto Teixeira de Freitas, Atti, in "Augusto Teixeira de Freitas e II Diritto Latinoamericano, org de Sandro Schipani. Pádua: Cedam, 1988 p. 13). Um homem que, por estes tracos, poderia ser tido como voltado ao passado, mas que foi, primordialmente, um personagem de antecipacốs, nascendo, deste paradoxo, sua glória e sua tragédia.

2. A propósito, veja-se os estudos de José Carlos Moreira Alves, "A formação romanística de Teixeira de Freitas e o seu espirito inovador"; Nelson Nogueira Saldanha, "História e Sistema em Teixeira de Freitas"; Orlando de Carvalho, "Teixeira de Freitas e unificaçáo do Direito Privado", e José Luis de los Mozos, "Aproximación metodologica al sistema de Teixeira de Freitas (a través de la distinción entre obligaciones e derechos reales y a proposito de la posesión", todos integrantes do volume "Augusto Teixeira de Freitas e il Dinitto Latinoamericano", Atas do Congresso internacional do centenário de Teixeira de Freitas, Roma 12/14 de dezembro de 1983, org. de Sandro Schipani, Pádua: Ed. Cedam, 1988, e ainda o meu estudo "Da Boa-Fé no Direito Privado sistema e tópica no processo obrigacional", Ed. Revista dos Tribunais, no prelo.

3. Leibniz não é classificável, segundo as categorias hoje dominantes, nem só como um filosofo, ou um matemático, ou um lógico, ou um jurista. Foi um "maître penseur", numa época em que as fronteiras entre as ciências não eram rígidas como hoje, onde a Logica e a Mour Fe misturavam os "antigos" - a tradiçáo escolástica - com os "modernos", Bacon e Campanella, Galleu, Kepler e Descartes e ainda Hobbes. Nestes descobre Leibniz ainda estudante em Leipzig, com pouco mais de quinze anos, "une méditation sur l'unite et tharmoni du monde, une Logique, une Méthode bien differénte de celle d'Aristote qui avait failli le conduire au verbalisme: le souci de
l'expérience". (Yvon Belaval, "Leibniz - Initiation a sa philosophie". Paris: Lib. Philosophique J. Vrin, 1984. p. 33).

4. Assim, José Luis de los Mozos, "Aproximación metodologica al sistema de Teixeira de Freitas(a través de la distinción entre obligaciones y derechos reales y a proposito de la posesión), in "Augusto Teixeira de Freitas e il Diritto Latinoamericano", cit., pp. 465 a 486, no qual , a c comparar Freitas e Velez Sarsfield, apontando às suas diferenças, dirá; "Esta diferencia, por lo demás, en el origen de la formación juridica, cultural y humana de nuestro autor tiene un nombre próprio: G. V. Leibniz, en cuya influencia hay que encontrar un factor decisivo, constante y duradero a pesar de otras influencias posteriores"(p. 469). Não logra o civilista espanhol, todavia, a anotar punctualmente essa influência, salvo no que concerne à construçăo do Esboço com base na distinção entre os direitos reais e pessoais. Também Orlando de Carvalho, in "Teixeira de Freitas e a Unificação do Direito Privado", in "Augusto Teixeira de Freitas e il Diritto Latinoamericano", pp. 101 a 153. (A referência a Leibniz encontra-se em várias notas, vo nota 41, p. 117, Anexo I, pp. 141 e 142 e Anexo II, p. 150), ainda José Carlos Moreira Alves, em "A formaçäo romanística de Teixeira de Freitas e o seu espírito inovador", in "Augusto Teixeira de Freitas e il Diritto Latinoamericano", pp. 17 a 39, localizandose a referência a Leibniz na p. 27. Nelson Nogueira Saldanha, em" História e Sistema em Teixeira de Freitas". p. 54, Francisoo des Santos Amaral Neto, em "A técnica jurdica obrancisco dos Santos Amaral Neto, Freitas e il Diritto Latinoamericano", pp. 155 a 170, em especial p. 157, e Sillvio Meira ("Teixeira de Freitas, o jurisconsulto do
Império - Vida e Obra", Rio de Janeiro, 1979, em especial Xl e XII).

5. Esta noção parece resultar do método exposto por Leibniz in "Nova methodus docendae discendaequae jurisprudentiae, obra escrita em 1667, e que era do conhecimento de Teixeira de Freitas, como alude este expressamente na Introdução à Consolidaçáo das Leis Civis, XLIX, embora pareça ser de seu conhecimento indireto, através da Dissertatio, de Blondeau.

entendida esta como a relação entre os ele mentos de um sistema ${ }^{6}$

Acolhendo estas inestimáveis lições, proponho adotar outro viés de análise, qua seja, o exame da matriz filosófica da noção de sistema, tal como entendida na acepção que lhe foi conferida por LEIBNIZ nos seus escritos propriamente filosóficos, em especia nos Novos ensaios sobre o entendimento hu mano ${ }^{7}$, escritos entre 1701 e 1704.

Não obstante não me tenha sido pos sível detectar se TEIXEIRA DE FREITAS teve ou não conhecimento desta obra ${ }^{8}-\mathrm{e}$ tendo presente a observação de NELSON NOGUEIRA SALDANHA, segundo o qual TEIXEIRA carecia de uma formação filosófica "que fosse além da mínima" - encontro na matriz filosófica da noção de sistema que adotou e, principalmente, nas observações que fez ao Esboço notáveis coincidências de pensamento, por vezes ex presso por idênticas metáforas o que, por si só, justifica esta investigação, ainda primária e provisória. Assim sendo, para que este estudo comparativo tenha êxito, mister que se examine, primeiramente, a noção de sisseguir, na obra de TEIXEIRA (II). tema em LEIBNIZ (I), visualizando-se, a

\section{O sistema em Leibniz}

Como é por todos sabido, a noção de sistema como "conexão imanente" é fruto de uma longa história cujo ápice será alcançado pelos filósofos jusracionalistas, restando perfeitamente delineada, no plano intelectual, apenas com os filósofos-matemáticos da linha germânica - LEIBNIZ e WOLF, notadamente - através das suas teorias a respeito da formulação das normas jurídicas como proposições ordenadas, completas e perfeitamente coligadas entre si, hábeis a formar - como dirá TEIXEIRA DE FREITAS muito mais tarde - não um mero "arranjamento e superposição, mas um tecido um aggregado de partes reciprocamente unidas $^{10 "}$.

Diferentemente de uma mera ordenação classificatória de elementos seguida pelos jusracionalistas de cariz francês, o sistema proposto pelos filósofos matemáticos da linha germânica se quis constituído através da precisão "científica" das suas premissas, através de formulações cada vez mais gerais, passíveis de redução a verdades intangíveis. $\mathrm{O}$ objetivo, por certo, não foi 0 de reduzir todo o conhecimento filosófico ao conhecimento matemático, mas sim de-

6. A noção de estrutura, correlata a de sistema, é posta por Mario Losano, in "Sistema e Struttura nel Diritto", vol. 1, Ed. Turim: Giappichelli, 1968, p. XXIII.

7. "Nouveaux essais surl Ientendement humain par I 'Auteur du Système de I Harmonie Préetablie", redigidos entre 1701 e 1704, $\theta$ publicados em 1765, que li na tradução de Luiz João Baraúna, São Paulo: Nova Cultural, 1992.

8. Segundo Orlando de Carvalho a inferência que se pode fazer, na obra de Teixeira de Freitas, a um pensamento monadológico "não significa tanto que Freitas conhecesse a metafísica de Leibniz, quanto que nele se repercutem (...) os prenúncios que na obra do jurista juvenil já existem da obra ulterior do filósofo". (Op. cit., Anexo II, p. 150). Também Nelson Nogueira Saldanha assinala que Teixeira de Freitas, embora tenha se referido diversas vezes a Leibniz, "chamando-o pelos mais reverentes adjettvos", provavelmente não o leu diretamente (Op. cit., p. 54, nota 15).

9. Op. cit., p. 59. Assim também a observaçáo de Beviláqua, para quem, em Teixeira de Freitas "a filosofia não alcançou vóos mais altos". ("Linhas e perfis jurídicos", Rio de Janeiro, 1930. p. 131, apud Orlando de Carvalho, op. cit., p. 141).

10. "Nova Apostilla à Censura do Senhor Alberto de Moraes Carvalho sobre o Projecto do Codigo Civil Portuguez". Rio de Janeiro: Typographia Universal de Laemmert, 1859. p. 52. 
finir a ordem da razão - aquilo que estrutura o sistema - ao modo das ciências matemáticas: analogia more geometrico, portanto, a qual requer a elaboração de um sistema centralizado no qual, no dizer de MENEZES CORDEIRO, " a ordenação não se consegue com base em conexões estabelecidas entre elementos periféricos pré-sistemáticos, ela desenvolve-se, antes, unitária e metódica, de uns quantos princípios firmados com vista ao siste$m a^{11 "}$.

Por isso o sistema se fundará em "proposições primeiras" que não requerem demonstração justamente por serem "verdadeiras" ou "inatas", assim como o são os princípios primeiros da matemática ou da geometria, de onde se seguem, ordenadas e unitariamente encadeadas, proposições secundárias e efeitos que constituem uma totalidade.

Analisando a noção de sistema em LEIBNIZ afirma MARIO LOSANO ${ }^{12}$ que, em sua obra o termo adquire uma dúplice significação: uma, atécnica, referida sobretudo à exposição de uma certa matéria e outra, específica, na qual o termo sistema designa não como o mero acostamento de elementos, mas, sobretudo, o conjunto das demonstrações destes fatos, conformando ordem científica perfeita na qual os particulares elementos devem ser expostos com base na maior ou menor simplicidade da sua demonstração ${ }^{13}$. Nesta acepção, percebe LOSANO, "sistema se enriquece de uma ul-

terior qualificação: não é apenas um discurso dedutivo, cujas partes são logicamente conexas mas é também um discurso que deve fundar a dedução sobre certos princípios, assim como ocorre no raciocínio matemático ${ }^{14}$ " O que significa dizer que, pressuposta à noção de sistema está a existência de certos princípios, existentes de per si que o fundam e o conformam.

É em direção à análise destes princípios, de sua conformação e significado para a noção de sistema que devo agora prosseguir.

\section{a) 0 encontro das "verdades \\ imanentes"}

Visto o sistema não mais como o sim ples acostamento de elementos, mas, sobretudo um "sistema interno", racionalmente compreensível e racionalmente demonstrável, segundo categorias, conceitos e definições racionalmente apreensíveis, um problema, contudo, continuava a perturbar as análises filosóficas, qual seja, a de saber como enquadrar, nesse sistema, os "casos difíceis", apenas solúveis mediante a casuística.

LEIBNIZ teve o mérito de, pioneira mente, buscar solver este problema, e o fez mediante o estabelecimento do elo que realiza a necessária conexão ou convergência (sýmpnoia pánta ${ }^{15}$ ) entre os elementos componentes do todo: a harmonia ou conexão imanente derivaria da existência de "prin-

1. Antonio Manuel Menezes Cordeiro "Da Boa-Fé no Direito Civir, Coimbra: Almendina, 1984, p. 219.

12. Sistema e Struttura nel Diritto, p. 58.

13. Op. cit., p. 58.

14. Idem, p. 61, traduzi.

15. A expressão de Hipócrates está em "Novos Ensaios", p. 08. cípios primeiros", existentes por si sós e integrantes do próprio ser das coisas.

Sua originalidade - e nisto é "stupefacentemente moderno", como dirá GIOVANNI TARELLO ${ }^{16}$ - está no modo como capta os problemas do direito e como organiza metodologicamente os problemas de mais difícil solução, pois, ao contrário da opinião então corrente, segundo a qual as soluções das questões dúbias deveriam ser buscadas na prática, recaindo na casuística, entende haver, para cada questão dúbia uma única solução, a qual deveria $e$ poderia ser demonstrada. A solução que propõe é o estabelecimento de uma proposição jurídica verdadeira que pode ser descoberta se a argumentação partir de outras proposições jurídicas verdadeiras e já conheci$\operatorname{das}^{17}$

No debate que, mediante o imaginário diálogo entre FILALETO e TEÓFILO, trava com LOCKE, LEIBNIZ nega a existência de átomos ${ }^{18}$, rejeita a possibilidade de substâncias, ou "almas" que possam existir separadas ${ }^{19} \mathrm{e}$ afirma a existência de "princípios inatos", ou "verdades necessárias". Essas "verdades inatas", ou axiomas, estando interligadas, formam um sistema graduado ou escalonado, pois a natureza "nunca faz saltos ${ }^{20 "}$ ", provindo "as percepções grandes $e$ notáveis" "por graus daquelas que são excessivamente insignificantes para serem notadas ${ }^{21 "}$

16. in "Storia della Cultura Giuridica Moderna. Bolonha: II Mulino, 1976..., p. 136.

17. Tarello, "Storia...", p. 136

18. "Novos Ensaios", p. 07.

19. Idem, p. 11.

20. Idem, p. 10.

21. Idem, ibidem,

22. Idem, p. 11. e competindo à Razão "a qual nada escapa, compreender distintamente todo o infinito $e$ enxergar todas as razões e todas as conseqüências $^{22 "}$.

Nesta perspectiva, as "verdades imanentes" possibilitariam a constituição de um saber totalizante e escalonado, eis que estruturado sobre princípios internos, imanentes, que estão no interior, no próprio "ser" de cada ciência. Observe-se a seguinte passagem: "As verdades necessárias, quais as encontramos na matemática pura e sobretudo na aritmética e na geometria, devem ter princípios cuja demonstração independe dos exemplos e, conseqüentemente, também do testemunho dos sentidos(...) Também a lógica, a metafísica e a moral, uma das quais forma a teologia e a outra a jurisprudência todas as duas naturais, estão repletas de tais verdades necessárias e, por conseguinte, a sua demonstração não pode provir senão de princípios intermos que se denominam inatos. É verdade que não se deve imaginar que possamos ler na alma estas leis eternas da razão a livro aberto, como se lê o edito do pretor no seu livro sem trabalho e sem pesquisa; basta, porém, que possamos descobri-los em nós em virtude da atenção, sendo que a ocasião é fornecida pelos sentidos, e a seqüência das experiências serve ainda como confirmação à razão, mais ou menos como as provas ser- 
vem na aritmética para melhor evitar o erro de cálculo, quando o raciocínio é longo 23 ".

O que significa que existem proposições primeiras, com caráter autofundante, as "verdades necessárias" que são "inertes", as quais, todavia, podemos descobrir "à força da atenção". Descobertos os princípios internos ou "inatos" e as relações entre esses e os casos particulares - aqueles que provêm dos exemplos - tem-se um sistema racional e internamente articulado, a razão atuando para a formulação das conexões "pois só a razão é capaz de estabelecer regras seguras e de suprir o que falta nas regras que não são seguras, inserindo as suas exceções (e) só a razão é capaz de encontrar finalmente as conexões certas na força das conseqüências necessárias". Se encontradas as "conexões certas na força das conseqüências necessárias" é porque encontrados estiveram os "verdadeiros princípios das coisas nas unidades de substância" ${ }^{24}$.

Estas premissas, exaustivamente explicitadas nos Novos ensaios, re-iluminarão o exame de seu método, este sim conhecido por TEIXEIRA DE FREITAS, que expressamente alude, na Introdução à Consolidação, ao Nova Methodus doscendae discendaequae jurisprudentiae ${ }^{25}$, referindo-o também em várias passagens da Nova Apostilla à Censura do Senhor ALBERTO

23. Idem, p. 05 .

24. Idem, p. 24 .

25. Consolidação das Leis Civis, Garnier, $3^{a}$ ed., 1896, XLIX e nota 31, doravante designada "Consolidaçăo" e indicadas as referências à Introduçăo pelos números romanos.

26. Rio de Janeiro: Typographia Universal de Laemmert, 1859, doravante designado por "Nova Apostilla".

27. Cf. Cesare Vasoli, "Enciclopedismo, Pansofia e Riforma Metodica del Dinitto nella nova methodus di Leibniz", in Quaderni Fiorentini per la Storia del Pensiero Giuridico Moderno, Vol. 2, 1973, p.41, grifos do autor. guns ${ }^{28 ",}$ dirá LEIBNIZ, acentuando que, nas matemáticas, cuja excelência resulta do seu formalismo, as experiências não se realizam "sobre a coisa em si mesma considerada, mas sobre as características que nós substituímos em lugar das coisas ${ }^{29 "}$. Características formais, por certo, de modo que, se utilizado o método que propõe, o raciocínio, seja na Física, na Moral ou na Jurisprudência, será tão demonstrável quanto na Aritmética.

Assim sendo, propõe que, conhecidos os "princípios primeiros", e deduzidas, por via da Razão, todas as suas conseqüências, das maiores às menores, sejam atribuídas definições certas para cada coisa, cada elemento ou fenômeno: "É manifesto que se se puder encontrar caracteres ou signos próprios para exprimir todos os nossos pensamentos, assim exatamente e claramente como a aritmética exprime os números, ou que (a álgebra) a análise geométrica exprime as linhas, nós poderemos fazer, em todas as matérias, desde que elas sejam sujeitas ao raciocínio, tudo o que se pode fazer em Aritmética e em Geometria ${ }^{30 " .}$

Do que, e especificamente no que concerne à Jurisprudência, LEIBNIZ, investindo contra " a imensa multiplicidade das leis ${ }^{31}$ " dispersas "em imensos volumes, entre os quais não existe nem ordem nem concordância ${ }^{32}$ ", contra o tipo de aplicação que daí decorre, baseada em argumentos retirados da "razão das leis, razão que é por vezes a coisa mais incerta 33 ", propõe a elaboração de um código, conjunto de leis "a partir das quais cada um compreenderá facilmente seu dever em todos os negócios e onde não se poderá reclamar de não haver cumprido por ignorância ou de ter sido abusivo pela sutileza do direito ${ }^{34}$ " de modo a evitar os processos

28. "La vrai Méthode, prise dans toute son étendue est une chose à mon avis tout à fait inconnue jusquici, et n'a été practiquée que dans les mathématiques. Encore elle est imparfaite à 'égard des mathématiques mêmes, comme j'ai eu le bonheur de faire voire dans les mathemematiques. Encore elle est imparfaite à 'égard des mathématiques mêmes, comme j'ai eu le bonheur de faire voire
à quelques uns" (Couturat, L. "Opuscules ef fragments inédits de Leibniz, 153, apud Y. Belaval "Leibniz, Initiation a sa philosophie", à quelques uns"(Couturat, L. "Opuscules et frag
Paris: Lib. Philosophique J. Vrin, 1984. p. 124).

29. "sur la chose même, mais sur les caractères que nous avons substitués à la place de la chose" (Couturat, Opuscules..., p. 154, apud Belaval, "Leibniz...", p. 124).

30. Couturat, Opuscules..., cit., 155, grifado no original, apud Y. Belaval, "Leibniz..., p. 125

31. G.W.Leibniz" De la Justice et du Nouveau Code", 1678 (data provável) In "Trois Textes sur le droit et la codification", transcritos por René Sève, In APD. Vol. 31, Paris, 1986. pp. 357 a 367. No original: "Nous avons décidé d'embrasser l'immense multitude des lois avec clarté dans peu de mots, afin que la mémoire des hommes ne soit pas surchargée et que le jugement ne soit pas plus longtemps fluctuant à cause de l'incertitude des opinions. Et ainsi le droit sera finalement achevé et certain (finitum certumque) (p. 360).

32. Idem, ibidem. No original: "Elles (as causas do direito incerto) sont assurément difficiles parce qu'elles sont contenues à l' état dispersé dans d'immenses volumes, parmi lesquels parfois il n'y a ni ordre ni accord. Les mêmes lois sont très souvent employées en diferentes causes et de differentes manières (...). De plus, dans um même corps de lois des dispositions antérieures sont en diferentes causes et de differentes manières (...). De plus, dans

33. Idem, p. 361: "Or on cherge d'ordinaire ces arguments dans la raison de la loi, raison qui est parfois la chose la plus incertaine: en général il ne faut pas accorder que l'autorité des interprètes est telle qu'lils peuvent étendre l'avis d'une loi (sententiam legis) des choses semblables, surtout lorsque des lois elles-mêmes semblent tantôt admettre tantôt rejeter ce mode d'argumentation et que l'estimation de la similitude est incertaine; et on a même l'habitude de tirer pour soi, à partir des lois, des axiomes ou des règles de droit, qu'ensuite on utilise pour définir des causes, mais que cependant sont affaiblis de touts cótés par des distinctions et perdent leur fonction: car les lois elles mêmes nient que l'on doive tirer le droit à partir de règles de cette sorte".

34. Idem, p. 358. 
"recobertos de trevas de tal sorte que raramente uma causa de alguma importancia é tratada sem que, mesmo entre os especialistas, nasçam controvérsias extremamente embaraçantes ${ }^{35 "}$.

A este código - que, todavia, não chegará a ser efetivo, pois ainda seria um impossível histórico - subjaz a noção leibniziana do direito como um sistema deduzido da demonstração das verdades imanentes, às quais correspondem definições certas, relativas a proposições que se articulam internamente, "ligando sujeitos (jurídicos) a predicados (jurídicos)", proposições que "são verdadeiras" (porque demonstráveis pelo raciocínio, como nas matemáticas), "e das quais com regras de transformação das proposições que se encontram na ciência lógica, podemos assim alcançar outras proposições (jurídicas) verdadeiras e incluidas no sistema jurídico ${ }^{36 "}$.

Como é por todos sabido, o método de LEIBNIZ foi prosseguido pela Pandectística alemã notadamente a partir das formulações que lhe conferiu WOLF,

espelhando-se, por suas grandes linhas, no BGB. Muito antes desta corporificação legislativa, contudo, veio refletir-se, entre nós, no sistema proposto por TEIXEIRA DE FREITAS que, expressamente, buscou o seu aperfeiçoamento e desenvolvimento último.

\section{O sistema em Teixeira de Freitas}

Atentíssimo leitor de SAVIGNY e dos juristas germânicos tributários das concepções leibnizianas ${ }^{37}$, percebe TEIXEIRA DE FREITAS que o filósofo de LEIPZIG, apesar do "poder do seu gênio 38 ", não alcançara retirar a melhor aplicação da "verdade eterna" que havia posto, e que nem esta havia sido perfeitamente assimilada pelos que lhe haviam seguido.

Disposto a empreender esta tarefa e ir às últimas conseqüências das proposições de LEIBNIZ, assim organiza a Consolidação - estruturando-a na divisão entre uma Parte Especial, composta pela divisão fundamental dos direitos pessoais e reais ${ }^{40}$, à qual

35. Idem, p. 360, no original: "En effet, nous avons appris que, par le vice des hommes et des temps, les procès sont recouverts de ténèbres de telle sorte que rarement une cause de quelque importance r'est traitée sans que même entre les spécialistes (peritos) ne puissent naitre des controverses assez embarassantes (perplexae).

36. Assim G. Tarello no original: "(...) una concezione del diritto comme sistema di proposizione; proposizioni che conettono a sogetti (giuridici) predicati (giuridici); proposizioni che sono vere, e dalle quali, con regole di trasformazione delle proposizioni che triviamo nella scienza logica, possiamo percio pervenire ad altre proposizione (giuridiche) vere, e incluse nel sistema giuridico". ("Storia..." cit., pp. 133).

37. Critica acerbamente Teixeira de Freitas os juristas filiados à Domat e Pothier, ainda presos demasiadamente ao sistema sciencia do Direito, associando-se à história a a philologia tem alcancado os mais brithantes triunfos" "Consolidaçäo" cit dII.

38. Introduçăo à Consolidaçăo, XLIX.

39. Idem, LI.

40. Afirma o nosso jurista que, com aquela divisão, se alcançaria o desaparecimento da diferença entre os direitos reais e os direitos pessoais, "differença tăo importante que é a chave das relaçōes civis". E esta distinçăo tem o caráter de chave para a compreensăo da ordem de arrumaçăo das matérias concernentes às relaçóes civis justamente, porque é sistemática, isto é, guarda consonância, externamente, com aquilo que é internamente_dotado de uma "organizaçăo" ou sistema imanente. Ao ignorá-las, o nância, externamente, com aquilo que é internamente_dotado de uma "organização" ou sistema imanente. Ao ignorá-las, o
chamado "sistema" das Pandectas, portanto - assim como o do Code Civil Français - tem muito mais de "ordenação" do que de chamado "sistema" das Pandectas, portanto - assim como o do Code Civil Français - tem muito mais de "ordenaçáa" do que de
"sistema" - no sentido que lhe será emprestado pela ciência alemã como o modelo próprio ao desenvolvimento de raciocinios "sistema" - no sentido que lhe será emprestado pela ciência alemá como o modelo prop

Revista da Faculdade de Direito da UFRGS, v. 17, 1999 "antecede uma Parte Geral, que lhe serve de prolegômenos ${ }^{41}$ ". Não me deterei no exame desta estrutura, já suficientemente iluminada pelos estudos existentes, apenas assinalando que, à Parte Geral, cabia tratar dos "elementos constitutivos de todas as relações jurídicas, e portanto das relações jurídicas na esphera do Direito Civil", isto é, as pessoas e as coisas. $O$ que quero sublinhar é que, para FREITAS, esta distinção era derivada "do producto da analyse de todos os direitos possíveis na sua extensãa ${ }^{42}$ ", isto é, não só os elementos constitutivos do direito subjetivo, mas, sublinho, todos os direitos possíveis, $\mathrm{e}$ em toda a sua extensão, tarefa omnicompreensiva própria de quem perspectivava, no Direito Civil, a existência de um sistema, e de um sistema apto ao contrário de uma mera ordenação classificatória - a promover a cobertura total da instância normativa.

Ora, o que me parece digno de nota é que uma tal estrutura só seria possível se tivesse como premissa a existência, em cada ser, em cada instituto jurídico, de um princípio primeiro, fundante e verdadeiro, princípio inato, radicado no interior do próprio ser, e do qual derivariam, como conseqüências necessárias, as demais regras, tal como havia proposto LEIBNIZ. Este princípio denominou TEIXEIRA DE FREITAS de "a unidade superior" através da qual podem ser deduzidas as relações que compõem os institutos e as regras da legislação.

\section{a) 0 encontro da "unidade superior"}

Já na Consolidação, que precedeu em cerca de quarenta anos a estrutura realizada no $\mathrm{BGB}^{43}$ resulta, do espírito sistematizador de TEIXEIRA DE FREITAS, a capacidade de pensar conceitos e concepções dotados do mais alto grau de generalidade e abstração tal como só posteriormente ingressariam no patrimônio jurídico contemporâneo. Sabia discernir, com precisão, o código - como espelho do sistema que seria próprio e imanente ao "ser" do Direito - e aquilo que, produto de uma mera ordenação, nada mais constituiria do que "um livro com letreiro de Código Civil, à feição do nosso Código Comercial vigente 44 ". O exame punctual de certas passagens de sua obra indicará até que ponto abeberou-se das concepções leibnizianas e até que ponto conferiu-lhes vida e corporificação, levando-as às últimas conseqüências, talvez não imaginadas pelo filósofo.

Preliminarmente ao exame de sua obra inacabada será importante fixar alguns pontos. Em primeiro lugar, os traços marcantes da noção de sistema no direito civil, que endossa uma noção vincada fortemente pelo acento ao método, um método, contudo, que não é meramente externo, não é só clareza e uma ordenação mais ou menos arbitrária. Um método que inicia

41. "Consolidaçăo das Leis Civis", Introdução, CXII.

42. Consolidação, CXIII, grifos do autor.

43. Segundo Silvio Meira ("Clóvis Bevilácqua, Sua Vida. Sua Obra", Fortaleza: EUFC, 1990. p. 114), alguns autores europeus consideram Teixeira de Freitas, por esta concepção, influenciador do Código Civil Alemão. Assim, Raoul de la Grasserie ("Lois Civiles du Brésir, Paris: Ed.Giard \& Briere, s/d).

44. Apud Levi Carneiro, "Estudo crítico-biográfico", p. XIV, introduzindo a ediçăo de o Código Civil - Esboço, Rio de Janeiro: Ed. Ministério da Justiça e Negócios Interiores, 1952, doravante denominado Esboço. 
com a organização do imenso cipoal legislativo que havia resultado das Ordenações e das leis extravagantes, mas que segue adiante, e resulta, como havia ensinado LEIBNIZ, do "interior do ser" do direito. Será melhor permitir que TEIXEIRA DE FREITAS fale por si, explicando-nos, passo a passo, como lhe ocorreu esta noção:

"Quaes os verdadeiros limites da Legislação Civil? Quaes as disposições actualmente em vigor? Qual o teor de sua ordenação própria? Os entendedores da materia, aquelles que conhecem o estado na nossa Legislação, sua incerteza, seus elementos heterogêneos, podem bem avaliar a difficuldade destas questões. Nunca tivemos Codigo Civil, e se por tal reputassemos o corpo das ordenações Filippinas, ou antes o $4^{\circ}$ livro dellas, que mais se dedicou aos contractos e sucessões estariamos ainda assim envolvidos na immensa teia das leis extravagantes, que se tem accumulado no decurso de mais de dois seculos e meio ${ }^{45}$ ".

O que significa que, uma vez detectado o problema, é preciso:

“... examinar as leis em seus próprios textos sem influencia de alheias opiniōes, comparar attentamente as leis novas com as antigas, medir com precisão o alcance e as conseqüências de umas e outras; eis o laborioso processo que empregado temos para conhecer a substância viva da Legisla- ção ${ }^{46}$," a "substância viva" que anima as leis, que desenha a ordem que lhe é própria e desfaz a "imensa teia", o que só é possivel através da meditação solitária, dos estudos e da reflexão, único caminho para o encontro da unidade superior, como dirá em célebre passagem:

"Para achar (...) os limites do Direito Civil, e a norma de exposição das matérias, que lhe pertencem, recorremos a estudos de outra natureza, consultámos os monumentos legislativos, revimos e meditámos as tradições da Sciencia; e com livre espírito procuramos essa unidade superior, que concentra verdades isoladas, penetra as mais recônditas relações e dá esperanças de um trabalho conscencioso 47 ".

Veja-se, neste trecho, o reflexo imediato das considerações leibnizianas acerca das noções ou princípios inatos, expostas no diálogo entre FILALETO e TEÓFILO acerca do sistema que este último vem de formular: "Encontro", diz TEÓFILO, "os verdadeiros princípios das coisas nas unidades de substância que este sistema introduz, e na sua harmonia preestabelecida pela substância primitiva ${ }^{48 " .}$

"Substância interior que penetra as mais recônditas relações", para FREITAS, "princípios existentes nas unidades de substância" ou "substância primitiva", para o filósofo alemão, princípios "inatos" porquanto assim entendidos os que "não temos necessidade de ir buscar fora ${ }^{49 "}$ existentes que são

\section{5. "Consolidação das Leis Civis", XXXI e XXXII.}

\section{Idem, ibidem, grifei.}

47. Idem, XXXIV, grifos meus.

48. "Novos ensaios", p. 24.

49. Idem, p. 35 .

Revista da Faculdade de Direito da UFRGS, v. 17, 1999 "no ser das coisas" 50 " - assim havia dito LEIBNIZ - muito embora possam carecer de demonstração, "como a verdade dos números, que estão em nós muito embora as aprendamos, seja por via demonstrativa, seja comprovando-as por exemplos ${ }^{51}$ ", uma vez que a sua percepção "depende de uma atenção $e$ de uma ordem ${ }^{52 "}$.

Em todo o caso, sempre "causas determinantes" - dirá FREITAS - de cuja escolha "depende a solução do problema ${ }^{53}$ ", causas inatas, que não devem ser arbitrariamente escolhidas fora do ser, uma vez que este não constitui "tabula rasa, como lousas nas quais não existe nada escrito ${ }^{54 " ~-~ e s c r e-~}$ vera LEIBNIZ - uma vez que "o homem é o ente inteligente e livre, e não uma tabula rasa em que o legislador constrói codificações arbitrárias" - assim enunciará TEIXEIRA DE FREITAS, ao comentar o art. 36 do Esbo$c ̧ o^{55}$, no seu sentir a "pedra angular de todo o Direito Civil que for legislado sobre a base da natureza humana ${ }^{56 "}$. Ilumina-se, por este viés, a sua célebre expressão contida no mesmo comentário - "as leis são feitas para o homem, e não o homem para as leis ${ }^{57 "}$. E assim é porque o princípio que as anima já

\section{Idem, p. 36}

51. Idem, p. 36.

52. Idem, p. 37

53. "Esboço", comentário ao art. 4", p. 7.

54. "Novos ensaios", Prefácio, p. 4.

55. Art. 36: "Sempre se entenderá que lhes são (às pessoas de existência visivel) permitidos todos os atos e todos os direitos, que Art. 36: "Sempre se entenderá que lhes sáo
não lhes forem expressamente proibidos".

56. "Esbocso", p. 39.

57. Comentário ao art. 39, "Esboço", p. 39

58. Idem, ibidem.

59. Leibniz, "Novos Ensaios", p. 39 .

60. "Novos ensaios", p. 35.

61. Nova Apostilla, p. 52, grifos originais. existe e não suporta intervenções arbitrárias, porque "a obra nós a temos e apenas se a modifica tanto quanto é preciso para o bem comum $^{58 " .}$.

Percebido o princípio, havia ensinado LEIBNIZ, "pode-se tirar dele conseqüências científicas" 59 ", pois "a razão das verdades mais particulares depende das mais gerais, das quais são apenas exemplos 60 ". A tarefa do legislador que o percebe é alcançar estas conseqüências em toda a sua extensão e assim, distinguir, dividir, definir. "Classificar", dirá FREITAS:

"não é simplesmente dividir, não é somente designar por uma denominação comum os indivíduos que se assemelhão a certos respeitos. A divisão é instrumento da analyse; mas, terminada esta, e conhecidas as differenças e semelhanças dos entes ou factos observados, a classificação, instrumento da synthese, os dis. tribue, não em series isoladas, mas em classes superiores e inferiores, subordinadas umas às outras, e formando um verdadeiro systema, que não é um simples arranjamento e superposição, mas um tecido, um aggregado de partes reciprocamente unidas ${ }^{61}$." 
Nas Notas ao Esboço, chegará a confessar: "Estas divisões e distinções, conheço que são mais próprias da doutrina, que da lei; ma sem elas é impossivel bem compreender o pensamento da lei, e fazer de suas disposições uma idéia exata". Todas as nossas divisões e distinções não aparecem no Projeto como simples adorno científico, do mesmo modo que as definições; "deve-se entender que são de caráter imperativo, ou concomitantes de disposições imperativas ${ }^{62 "}$.

A classificação, a divisão, a distinção, não sendo arbitrárias, não provindo da es. colha aleatória de um número - como o que encantara o monarca das Siete Partidas nada mais são, portanto, do que o produto de um princípio dominante ${ }^{63}$, pois "se a classificação não é fundada sobre um princípio, não existe systema ${ }^{64 "}$.

Note-se que as proposições leibnizianas a respeito dos princípios inatos, da necessidade de sua demonstração e do alcance de suas conseqüências eram, no seu entender, também válidas para as ciências de ordem prática, chegando a afirmar que não existiriam, aliás, princípios de ordem prática que não fossem inatos ${ }^{65}$ ". Havia escrito LEIBNIZ: "a ciência moral (...) é inata da mesma forma que o é a aritmética,

pois depende também das demonstrações que a luz interna formece ${ }^{66 "}$. O que é inato, ensina TEÓFILO, "nem por isto é logo conhecido clara e distintamente: necessita-se por vezes muita atenção e ordem para percebê-lo, sendo que as pessoas de estudo nem sempre o atingem, muito menos qualquer criatura humana ${ }^{67 "}$.

"Cem vezes vacilei", confessará TEIXEIRA DE FREITAS, na nota ao art. 276 do Esboço, dando conta da profundidade do seu meditar sistemático: devia ou não contemplar as sociedades anônimas como pessoas jurídicas, e a par das corporações, posto diferirem, ambas, na sua duração? Mil vezes meditou, porém, e chegou à conclusão de que a diferença não era fundamental, que havia um caráter comum às duas espécies ${ }^{68}$. Aí percebe-se o seu imenso esforço para, à força do estudo e da meditação visualizar, no "ser" dos vários institutos que classificava e sistematizava, a sua "verdade inata", o seu "princípio superior", a "substância viva", o "princípio comum" que permitiria a classificação perfeita das várias regras jurídicas, deles decorrentes ${ }^{69}$. Daí também o seu manifesto horror ao "detestável espírito das leis francesas ${ }^{70 ", ~ " p a s t a ~ d e ~ c o n f u s o s ~ e l e m e n t o s ~}{ }^{71 "}$ que tão acerbamente critica em várias passagens das

62. "Esboço", nota ao art. 274, p. 161, grifei.

63. Nova Apostilla, p. 53

64. Idem, ibidem.

65. Leibniz, "Novos Ensaios", p. 39.

66. Idem, p. 42.

67. Idem, p. 45.

68. "Esboço", nota ao art. 276, p. 165.

69. Veja-se, como exemplo, a nota ao art. 40, do "Esboço", justificativa da distinção e classificaçáo entre pessoas capazes e incapazes, um dos pontos altos do seu pensamento.

70. "Esboco", p. 8, nota ao art. 5?.

71. Nova Apostilla, p. 72.

notas ao Esboço e da Nova Apostilla. Horror à assistematização, às noções "errôneas confusas" que adviriam de uma inexata compreensão do sistema que propunha, fundado na verdade do ser, encontrável pela atenta observação à "realidade da vida"

Com efeito, tinha TEIXEIRA como certo que as verdades das coisas, ou princípios, ou idéias, constituíam, como havia afirmado LEIBNIZ, "a alma e a conexão" dos nossos pensamentos ${ }^{73}$, sendo "ali necessários, da mesma forma que os tendões e os músculos o são para andar, embora não pensemos neles ${ }^{74 "}$. Mesmo quando da elaboração da Consolidação - quando o intuito ainda não era o codificatório, mas o de ordenar e, classificando, tornar clara a confusa massa legislativa existente - transparece, nítida, a preocupação de ordenar e classificar à vista das conexões imanentes dos institutos, à vista da "unidade superior" que preside a "substância viva" do direito, o que o levou, na justa observação de ORLANDO DE CARVALHO, a situar o sistema "como matriz do problema, de relevo quase impar entre os juristas de seu tempo ${ }^{75 " .}$.

E foi ímpar porque, no Esboço, "ponto culminante de sua obra" e, no qual "o seu espirito criador encontra terreno propício para evidenciar-se ${ }^{m 6}$, levou às últimas conseqüências esta concepção, o que pode ser exemplificado com o exame de dois temas,

quais sejam, o da unificação do direito privado - no qual a questão da unidade sistemática da matéria privada levada às últimas conseqüências - e do caráter das disposições da Parte Geral, que virá a reformular.

É neste último ponto que desejo enfocar nossa atenção, tomando como exemplo paradigmático das concepções leibnizianas que acolheu a riquíssima nota ao art. 431, que introduz a Secção III do Esboço. Aí vem expresso o método que deriva da sua concepção de sistema, método que explica e justifica a estrutura do Código que propôs:

\section{b) 0 método}

Na nota ao art. 431 TEIXEIRA DE FREITAS justifica a reformulação do seu pensamento concernentemente à inclusão dos fatos jurídicos na Parte Geral, revelando três traços que, por fundamentais, devem ser aqui registrados: a "aderência ao real", que perseguia - porque a verdade das coisas está nelas, inata; o domínio extremo da dogmática, na qual foi um mestre e, por fim, o caráter sistematizador, no sentido moderno, aquele que fora posto por LEIBNIZ e que irá permitir, por força da delimitação de proposições primeiras, os "princípios mais gerais", o perfeito encadeamento dedutivo entre os gêneros e as espécies, bem.como a sua possibilidade de articulação centralizada com

72. Esboço, p. 19, nota 17, em crítica à divisão das pessoas procedida pela doutrina francesa: "mas como fugir à divisão do noddo texto? A realidade da vida ai está, basta observá-la".

73. Leibniz, "Novos ensaios", cit., p. 35.

74. Idem, ibidem. E ainda: O espirito se apóia sobre esses princípios a todo o momento, mas nâo chega tão facilmente a distinguil-os e representá-los distinta e separadamente, visto que isto exige uma grande atenção ao que ele faz, e a maior parte das pessoas, pouco habituadas a meditar, não têm tal atenção"

75. Op. cit., p. 119.

76. José Carlos Moreira Alves, op. cit., p. 29. 
os demais elementos que compõem o universo jurídico, conduzindo, assim, à cobertura completa do ordenamento.

Importa registrar que já na Introdução à Consolidação TEIXEIRA DE FREITAS havia exposto os grandes lineamentos do seu método, que é o de, conhecido o quadro da legislação civil e o quadro das suas "divisões peculiares", fixar algumas "noções fundamentais, investigando a teoria dos direitos reais e a dos direitos pessoais e indicando, por último, a aplicação que se pode fazer dos princípios $77 "$. A classificação que propõe, contudo, não nasce da tradição - muito embora fosse notável romanista - mas da substância viva do direito, porque, "não pode haver verdadeira classificação do Direito sem que se derive das diferenças e conformidades que constituem a natureza das coisas ${ }^{78 "}$.

Assim explica a razão pela qual, modificando o critério exposto na Consolida ção, veio a incluir, no Esboço, os fatos jurídicos na Parte Geral. Ouça-se o que tem a dizer:

"Esta Secção 3a , que trata dos fatos, um dos elementos dos direitos regulados no Código Civil não estava em meu primitivo plano (...). Ali disse eu: alguns Escritores adicionam este terceiro elemento sob a denominação de fatos, fatos jurídicos, atos jurídicos, de que também tratam na parte geral das matérias do Direito Civil. Não nos conformamos com este método.

\section{7. "Consolidação", XII e XIII.}

78. Idem, XLIX.

79. "Esboço", p. 229, nota ao art. 431

80. Idem, ibidem.
Hoje, ao contrário, estou convencido de que sem este método será impossível expor com verdade a síntese das relações do Direito Privado, e fugir a um defeito gravíssimo de que se ressentem todos os Códigos, com exepção unicamente do da Prússia. Eles têm legislado sobre matérias de aplicação geral a quase todos os assuntos do Código Civil, do Código de Comércio e do Código do Processo, como se fossem exclusivamente aplicáveis só aos contratos e testamentos; e com este sistema embaraçam o exato conhecimento do Direito Privado, isolando fenomenos que são efeitos da mesma causa, e contribuindo destarte para que muitas espécies escapem à influência de seus princípios diretores ${ }^{79 "}$.

O encontro da "unidade superior" que permite não se isolem fenômenos que derivam das mesmas causas justifica, pois, a reformulação operada. Expostas as razões pelas quais considerou incluir os fatos jurídicos, elabora uma teoria dos fatos jurídicos, entendendo que os erros em que incorriam os códigos de particularizar disposições dotadas de "caráter próprio de omnicompreensãa $0^{80 "}$ aos contratos e testamentos foi superado "ao dar conta fiel", a Parte Geral, de "todos os elementos dos direitos", e justificando o seu raciocínio em passagem que só será igualada em rigor científico, na civilística brasileira, por PON. TES DE MIRANDA, escreverá:

"... assim como subi dos contratos e testamentos para os atos jurídicos, foi necessário remontar depois dos atos jurídicos para os atos lícitos em geral, dos atos lícitos para os atos voluntários, achando aí os atos ilícitos; e finalmente dos atos voluntários para os fatos em geral ${ }^{81}$ ".

O relevo que atribui à idéia de fato jurídico como elemento que está no topo de uma escala - pois bem discerne entre os fatos como causa e como objeto do direito é revelador do escalonamento ou estrutura graduada que o anima, tal qual havia sido impulsionada pelo filósofo alemão. Bem assim, a importância conferida à idéia de ato jurídico como dado potencialmente gerador e articulador de toda a instância normativa:

"Entram na ordem dos fatos de que trata esta Secção: estas palavras em nosso texto advertem que não se trata dos fatos como objeto de direitos, senão unicamente dos fatos como causa produtora de direitos. (...) Os fatos, objeto de direitos, e dos atos jurídicos, são sempre atos humanos positivos ou negativos, ações ou omissões. Os fatos, causa produtora de direitos, podem ser atos humanos, e podem também ser fatos exteriores em que a vontade não tem parte".

"Sem fatos que engendrem direitos, eis o pensamento fundamental do nosso artigo e da presente Secção, não pode existir direito algum no sentido em que o Projeto vai regular direitos na Parte Especial ${ }^{82 " . ~}$

Em carta a MARTIN FRANCISCO, então Ministro da Justiça, datada de 20 de setembro de 1867 , retoma este ponto:
"Na escala dos actos jurídicos entram as leis (...) As leis em grupo, e em outro grupo o resto dos actos jurídicos, são, em última análise, as únicas potências, a que se reduzem todas as causas jurídicas". (...) Actos em geral, actos voluntários, involuntários, jurídicos, probatórios, legislativos, governamentais, administrativos, judiciais, civis, comerciais, ilícitos, tal é a escala que percorremos, e bem se vê que as leis são atos legislativos, e que acima destes estão os actos jurídicos ${ }^{83} "$.

O que aqui percebo é a realização da proposição leibniziana da "verdade imanente" que, descoberta, põe a nu o mais profundo ser das regras jurídicas e permite o desdobrar encadeado de outras proposições. "Verdade imanente", contudo, que, em FREITAS, está fundamentalmente ata$\mathrm{da}$ à "realidade da vida" - e por isto superadora do simples geometrismo - vinculada que é ao que se passa, concretamente, na realidade:

"Eis a parte mais delicada dos meus trabalhos. Quem quiser meditá-la, conhecerá perfeitamente o jogo das relações humanas em todo o campo do Direito Privado, e nas suas duas divisões de Direito Civil e de Direito Criminal; saberá precisamente quais sejam seus elementos comuns, qual a linha que as separa. E, na órbita do Direito Civil, ficará na posse de um instrumento seguro para conhecer o mundo dos fatos, para resolver com exatidão todas as espécies, não se iludindo com a reprodução delas em sua variedade infinita ${ }^{84 "}$. 


\section{Conclusão}

Detectadas, assim, as semelhanças entre as matrizes do pensamento de TEIXEIRA DE FREITAS e de W. G. LEIBNIZ, seria o caso de, à guisa de conclusão, perguntar se o nosso jurista logrou realizar - como havia proposto, na Introdução à Consolidação - a superação do pensamento do filósofo de LEIPZIG, retirando a melhor aplicação da "verdade eterna" que aquele havia posto. $\mathrm{O}$ perfeito geometrismo teria sido superado no confronto com a realidade da vida?

O fato de sua obra não ter podido validar-se no plano da efetiva praxis, a superação, em nossos dias, da noção iluminista de sistema ${ }^{85}$, o essor da era decodificatória ${ }^{86}$ não permitem resposta conclusiva. Indícios, contudo, podem ser visualizados nas observações que, certeiramente, registram que, em TEIXEIRA DE FREITAS, a preocupação com o concreto do Direito ${ }^{87}$, com os seus aspectos sociais - preocupação percucientemente atribuída por MIGUEL
REALE à influência que recebeu de AHRENS e do krausismo ${ }^{88}$ - foi também uma constante, tão forte quanto a preocupação lógico-sistemática. Só por este dado, portanto, seria possível afirmar que não perdeu-se, o nosso civilista, no puro geometrismo abstratizante. Pelo contrário, o que no vigente Código Civil "morde (digamos) a realidade vem de TEIXEIRA DE FREITAS, ou de COELHO RODRIGUES", afirma incisivamente PONTES DE MIRANDA $^{89}$, referindo-se ao Esboço e ao Projeto de COELHO RODRIGUES. E a unificação, no Projeto do Código Civil, hoje em tramitação, das obrigações civis e comerciais - unificação que resulta da "idêntica substância" (como se diria em linguagem oitocentista) destas atividades, centradas que estão na categoria geral do negócio jurídico ${ }^{90}$ - constitui eloqüente tra ço do legado sistemático que nos transmitiu.

Campo Verde, agosto de 1999.

85. Acerca deste tema escrevi em "A Boa-fé no Direito Privado", capítulos $4^{\imath} e 5^{2}$.

86. "Essor" relativo, é bem verdade, que atingiu o seu auge nos anos 80 , com a extraordinária repercussão da obra de Natalino Irti, "L'Età della decodificazione" (1978). Hoje já se fala, contudo, na "era recodificatória", seja pela simples observação do fenómeno da codificaçăo, é certo que sob novas bases, já não mais centrado na preocupaçăo omnicompreensiva e totalizante que caracterizou a codificaçăo oitocentista, sendo exemplos, nos últimos 30 anos, os Códigos Civis de Portugal, Argentina, Grécia, Chile, Venezuele, Equador, Perú e, mais recentemente, Holanda, seja porque os próprios fautores da idéia descodificatória parecem ter voltado atrás em suas proposiçoses (nesse sentido, Natalino Irti, "I cinquent anni del Codice Civile", Rivista di Diritto Civile, 1992 Parte Prima, p. 227).

87. Assim, Nelson Nogueira Saldanha, op. cit., p. 65.

88. "Humanismo e realismo jurídicos de Teixeira de Freitas", in "Augusto Teixeira de Freitas e ll Diritto Latinoamericano", pp. 41 a 48, assinalando: "A referência a Ahrens me parece essencial, pois o conhecido Cours de Droit Naturel deste filósofo teuto constituiu uma das vias de penetração das idéias de Krause no Brasil". (p. 42).

89. "Fontes e Evolução do Direito Civil Brasileiro", Ed. Forense, 1981. p. 87

90. Nesse sentido, Miguel Reale: "Toda a vez que o negócio jurídico, disciplinado na parte do Direito das Obrigaçöes. adquire uma estrutura própria adequada à realizaçăo do fato econômico, surge a empresa". (In "O Projeto do Código Civil - Situação atual seus problemas fundamentais", Ed. Saraiva, 1986, p. 48).

Revista da Faculdade de Direito da UFRGS, v. 17, 1999

\section{José Luiz de Almeida Martins Costa - 100 anos de uma vida dedicada ao Direito ${ }^{1}$}

\author{
Gudith eMaxtins- Costa \\ Professora Adjunta na Faculdade de Direito da UFRGS. Doutora em Direito pela USP.
}

1 药 A missão da qual fui incumbida - falar sobre meu avô paterno, MARTINS COSTA ${ }^{2}$ - é, paradoxalmente, uma grata e uma ingrata tarefa. Grata é, sem dúvida, e basta a figura do homenageado, para mim, o "vovô Zeca", para que a missão seja, por si só, gratificante. Mas é também ingrata, difícil, porque é quase impossível separar a neta da analista. Neta primogênita, que tive a insuperável ousadia - diria até, a temeridade - de prestar concurso nesta $\mathrm{Fa}$ culdade para lecionar a disciplina de meu avô (e também de meu pai) e que hoje tentarei, num imenso esforço de objetividade, JOSÉ LUIZ DE ALMEIDA afastar as subjetividades do afeto, da emoção, do amor, das lembranças infantis, e vir aqui falar não só, ou não apenas do avô, mas do Professor.

Uma outra dificuldade se agrega ao meu esforço para ser objetiva. Não fui, ao menos do ponto de vista formal, sua aluna. Fui aluna de meu pai, professor ANTÔNIO DE ALMEIDA MARTINS COSTA ${ }^{3}$. Através deste, contudo, recebi o seu amor ao estudo do Direito Civil. E, por meio da curiosidade de jovem estudante desta Faculdade, que fascinada, espiava a biblioteca de meu avô, lia os memoriais, as razões de re-
1. Palestra pronunciada no Painel realizado em 8 de junho de 1999 na Faculdade de Direito da UFRGS, em sessão comemorativa do aniversário de 100 anos do Professor José Luiz de Almeida Martins Costa.

2. José Luiz de Almeida Martins Costa nasceu em Petrópolis, no Rio de Janeiro, em 16 de abril de 1899, durante viagem realizada por seus pais, José de Almeida Martins Costa Júnior, então secretário da Fazenda do Governo do Estado, e Maria do Carmo de Canvalho Martins Costa. Com menos de dois meses de idade, no entanto, veio para Porto Alegre, dizendo-se, por isto integramente mente gaucho. Fora 70 ano - 1969 quas da OAB/RS e Juiz Eleitoral quando da redemocratizaçăo, em 1946.

3. Advogado, foi Conseheiro da OAB/RS e Juiz Eleitoral e professor de Direito Civil da Faculdade de Direito da UFRGS entre 1959 e 1992 .

Revista da Faculdade de Direito da UFRGS, v. 17, 1999 